\title{
EL “DESCUBRIMIENTO” DE MÉxico. Chihuahua eN LA CRÓNICA DE GEORGE RuXTON
}

\author{
EDGAR ESPINOSA \\ JOSÉ VARGAS
}

Una posteridad más sabia que nosotros buscará cualquier noticia del pasado como si fuera una reliquia, y ni la vida de un solo hombre, por insignificante que esta sea, le será indiferente, porque en ella verá reflejada, con mayor o menor intensidad, toda la vida de una época.

(Novalis)

El modo más cómodo de conocer una ciudad es averiguar cómo se trabaja en ella, cómo se ama y cómo se muere.

(Albert Camus)

\section{RESUMEN}

$\square 1$ objeto de estudio es el libro Aventuras en México, crónica de George Ruxton. Escrita casi al mediar el siglo XIX, el W texto nos revela la visión adusta de un inglés sobre México y los mexicanos de entonces. Si bien, varias generaciones de mexicanos (desde Fernández de Lizardi hasta Sierra) escribieron innumerables páginas sobre lo "nacional", también hubo extran- 
jeros que hicieron lo propio. En el caso que nos ocupa, a Ruxton lo impulsó una curiosidad por el carácter exótico con el que vio a nuestro país.

Palabras clave: Chihuahua, siglo XIX, George Ruxton, Romanticismo, México

El presente trabajo tiene el propósito de identificar la representación que George Ruxton elabora sobre Chihuahua. Para lo anterior, tomamos su diario de viaje intitulado Aventuras en México, escrito hacia 1846 -año particularmente trascendente para el devenir histórico nacional-. La obra se publicaría aún en vida del autor y nos queda en forma de testimonio de cómo se externaban mediante la escritura actitudes, sensaciones, percepciones acerca de un país considerado "bárbaro", "inculto" y "exótico".

Nos parece relevante el planteamiento por tratarse de un extranjero (ciertamente no el único, ni siquiera el primero), que dejó testimonio de sus andanzas en esta parte del norte del territorio mexicano. Asimismo, dicho objeto de estudio nos permitirá advertir las premisas (culturales, ideológicas) mediante las cuales la tradición occidental ha montado un imaginario ("civilizatorio") sobre lo que entonces se consideró espacios coloniales.

En la delimitación geográfica que hoy tiene nuestro país, se tiene registro de la llegada y presencia de extranjeros que arribaron en distintos momentos. Varios de esos personajes dejaron testimonios por escrito (trabajos de investigación, cartas, memorias, diarios) donde plasmaron las impresiones que les causó el vasto espacio (recursos naturales, paisajes, clima, costumbres). De hecho, los hombres públicos del México decimonónico activos en los planos político e intelectual, empleaban el término "bellas letras" para referirse al cúmulo de actividades (opinión pública, deliberación política, divulgación científica, propaganda religiosa) que desarrollaron en diversas áreas (periodismo, novela, historia, ciencia, educación). A la obra impresa referida en sus distintas modalidades (libros, diccionarios, periódicos, calendarios, panfletos, crónicas, guías para viajeros) y épocas (virreinato o siglo XIX) la llamaremos literatura. 
El corpus literario al que aludimos, proponemos abordarlo a partir de la premisa que supuso el tránsito de dejar de ser Nueva España (antiguo régimen) para convertirse en México (Estado nacional moderno). Es decir, en este caso el siglo XIX fue una etapa de transición y reconstrucción. ¿Qué implicó dicho tránsito? Como se conoce, en el lapso que va de la etapa virreinal hasta la conformación del Estado moderno, se constituyeron muchas de las bases que aún sustentan la vida institucional del país. Sin embargo, en un vistazo a ese periodo de nuestra historia encontramos que dicho tránsito tuvo su grado de dificultad: y es que si bien se logró romper con el régimen colonial, durante décadas fue imposible instaurar otro estable y duradero; también están documentadas las incontables luchas intestinas que por distintos motivos (monárquicos-republicanos, centralistas-federalistas, conservadores-liberales, regiones-centro) se desataron en una sociedad heterogénea (mestizos, criollos, indígenas, mulatos, negros); otro aspecto conocido es el poco desarrollo de las vías de comunicación en el territorio mexicano, lo que incidió en el aislamiento de ciertas regiones, en la consecuente irrupción de cacicazgos (S. Vidaurri, por ejemplo), incluso en la separación de entidades (Texas lo consiguió, Yucatán lo intentó); asimismo, ciertas investigaciones indican la condición precaria -podría decirse al borde del colapso- de la economía nacional; por si todo esto fuera poco, hay que recordar las invasiones de los ejércitos estadounidense (1846-1848) y francés (1862-1866).

En un escenario por demás desventajoso que atentó contra la formación del Estado mexicano, de esta breve exposición se deduce algún tipo de respaldo o apoyo, hecho mano de un que las crisis políticas, militares y económicas fueron durante varias décadas obstáculos para la conformación y consolidación de lo "nacional". Dicho sentido del ser nacional se constituyó desde otro ámbito -un tanto despreciado ahora por las y los historiadores profesionales- como lo es el de las ideas, las palabras, la escritura, la literatura. Muestra del planteamiento anterior lo encontramos en un sinfín de esfuerzos editoriales producidos en distintas partes del país durante aquella centuria, como periódicos, revistas, catecismos, manuales, lecciones, diccionarios, tratados, historias, 
biografías, crónicas, novelas, cartillas, folletería, teniendo entre sus objetivos construir y fomentar un sentido de pertenencia. En otros términos, mientras las estructuras política o económica fueron incapaces por varias décadas de propiciar las condiciones necesarias para la constitución de la nación, los proyectos donde se difundían las ideas, las palabras y el pensamiento lograron dotar de sentido a ese ente nacional. ${ }^{1}$

Es cierto que la obrita que ahora abordamos circuló, en principio y durante mucho tiempo, para un público lector angloparlante (en primera instancia Inglaterra y, posiblemente, después Estados Unidos). Señalado lo anterior y para los propósitos del trabajo, lo consideramos una forma de representación en la cual se difundió - de manera indirecta si se quiere-, una idea de lo que entonces era México.

\section{VIAJEROS EN MÉXICO Y SUS TESTIMONIOS}

Un primer punto que consideramos medular para el presente trabajo y está en consonancia con el argumento anterior, es el relativo a la producción impresa que a lo largo de aquella centuria se desarrolló en el país. Parte de esa producción editorial estaba conformada por una oferta llamada "guías de forasteros". Dichos artefactos literarios, de hecho, comenzaron a circular desde el siglo XVIII, los cuales en su mayoría proporcionaban registros de nombres y direcciones. ${ }^{2}$ El propósito era difundir lo que ofrecían ciertos lugares (en especial, la ciudad de México) a quienes arribaban de otras regiones o personas que llegaban del extranjero; la información que difundían era acerca de almacenes, talleres, expendios y demás casas comerciales, cuyo objetivo era exponer que el desarrollo y la modernidad habían llegado a este país recién independizado. En estas condiciones, entre 1832 y 1899 al-

1 Espinosa Martínez, Édgar Iván (2009). "La construcción de lo 'nacional' desde las regiones. La Revista de Nuevo León y Coahuila, 1863-64”, Vetas. Revista de El Colegio de San Luis, número 30, año X, enero-junio, pp. 103-104.

2 Corvera Poiré, Marcela (2005). "Las guías de forasteros en el México del siglo XIX", La república de las letras. Asomos a la cultura escrita del México decimonónico, Vol. II, Publicaciones periódicas y otros impresos, edición Belem Clark de Lara y Elisa Speckman Guerra, México, Universidad Nacional Autónoma de México, pp. 253 y 254. 
gunos de los hombres públicos más notables (Juan Nepomuceno Almonte, Marco Arróniz, Ireneo Paz, Manuel Tornell), escribieron y les fueron editadas "guías" donde mostraban la fisonomía de la capital mexicana.

En consonancia con lo anterior, qué ejemplos tenemos de extranjeros que por alguna razón se encontraban en México en algún momento de aquella centuria. Todavía más, si -como señalamos-, la entonces recién constituida nación pasó décadas de inestabilidad, ¿acaso había algo que les atrajera a personas oriundas de otras latitudes? En esta línea argumentativa, mencionaremos algunos casos que nos servirán de referentes para justificar la elección de Ruxton y su reflexión sobre Chihuahua.

Antes de que nuestro personaje llegara al país y escribiera sus notas, ya existía un cúmulo de obra al respecto. De hecho, desde tiempos virreinales, conquistadores y colonos, militares y religiosos dejaron testimonios por escrito de su presencia y estadía en algún lugar del entonces septentrión novohispano. ${ }^{3}$ Hecha la acotación, en las siguientes páginas presentamos ciertos esfuerzos elaborados por extranjeros durante la primera mitad del siglo XIX; unos pueden ser más conocidos que otros y nos servirán como punto de partida.

Quizá debamos comenzar mencionando a Alexander von Humboldt (1769-1859) y su Essai politique sur le Royaume de la Nouvelle-Espagne. De origen prusiano, estirpe cortesana, educación ilustrada y talante liberal, Humboldt devino en viajero incansable; en una de esas estancias estuvo en América entre 1799 y 1803. ${ }^{4}$ Fruto de esa

3 A manera de ejemplo tenemos a Juan Agustín Morfi (1720-1783) y su Viaje de indios y diario de Nuevo México, escrito hacia 1777. Morfi fue un franciscano de origen gallego. Instalado en Nueva España, impartió cátedra en el Colegio de la Santa Cruz de Tlatelolco (Ciudad de México) y acompañó a Teodoro de la Croix (17171791) en la encomienda dirigida a reorganizar el vasto territorio hacia el norte del virreinato; así, entre agosto de 1777 y febrero de 1778, el militar y el religioso emprendieron un viaje que los llevó por buena parte del septentrión novohispano (incluido el actual estado de Chihuahua). De esta experiencia, Morfi tomó notas e hizo descripciones sobre distintos aspectos (históricos, geográficos, etnográficos, estadísticos) que plasmó en la citada obra. El trabajo llamó la atención de Manuel Orozco y Berra (1818-1881), quien lo editó por vez primera como parte del proyecto Documentos para la historia de México [1856].

4 Mentz, Brigida von (2011). “¿Espía prusiano?, ¿cortesano liberal?, ¿científico apolítico? Notas en torno al autor del Ensayo político sobre el reino de la Nueva España 
experiencia, el Essai publicado en París hacia 1811 representa una visión científica muy completa y bien documentada de la para entonces ya agonizante entidad novohispana.

Tras la disolución del orden colonial, hubo personajes que vieron en la nueva nación un espacio con condiciones idóneas para promover proyectos cuyo objetivo era configurar una sociedad distinta. Aunado a la forja que se daba en torno a la constitución del Estado mexicano, variadas formas de pensamiento hicieron su aparición, siendo una de ellas el mutualismo. Fue ese el caso de Benjamin Lundy (1789-1839), un estadounidense oriundo de Nueva Jersey que pasó algún tiempo en lugares de Coahuila (en este caso, Monclova) y Tamaulipas (tanto en la capital política-Ciudad Victoria- como en Matamoros). ${ }^{5}$ Opositor férreo al esclavismo y al contrabando, su testimonio lo plasmó en un Diario donde este cuáquero con pinta quijotesca expone de forma abnegada su intento por demostrar que es posible una sociedad de personas capaces de entenderse.

Lo anterior remite a otro personaje que décadas más tarde apareció de forma misteriosa y con una propuesta extravagante en México: Plotino Constantino Rhodakanaty. Se dice que Rhodakanaty nació en Atenas en los años de 1820 (unos señalan 1824, otros 1828), que estudió medicina en Berlín y que habría llegado a México hacia 1861. Participó en diversidad de proyectos, tanto editoriales (La Social) como de tipo organizativo (cooperativas obreras y agrícolas).

En el año de 1861 se editó una Cartilla socialista. A esta breve obrita le acompaña un subtítulo que indica: O sea, Catecismo elemental de la escuela socialista de Carlos Fourier. ${ }^{6}$ Su autor, P. C. Rho-

y del Cosmos, y el contexto prusiano-alemán en que vivió (1769-1859)", en José Enrique Covarrubias y Matilde Souto Mantecón (coords.), Economía, ciencia y política. Estudios sobre Alexander von Humboldt a 200 años del ensayo político sobre el Reino de la Nueva España, México, Instituto Mora, Universidad Nacional Autónoma de México, Instituto de Investigaciones Históricas, p. 31.

5 Javier Villarreal Lozano (2011). Tiempos de tormenta. La vida en Monclova, Coahuila; Ciudad Victoria y Matamoros, Tamaulipas, 1833 y 1834 / Diario de Benjamin Lundy, Estudio introductorio, traducción y notas de Javier Villarreal Lozano, Saltillo, Universidad Autónoma de Coahuila / Escuela de Ciencias Sociales / Plaza y Valdés, pp. 33-40.

6 Illades, Carlos (2002). Rhodakanaty y la formación del pensamiento socialista en México, México, Anthropos / Universidad Autónoma Metropolitana-Iztapalapa, p. 50. 
dakanaty, es un personaje que, hasta la fecha, es un enigma en muchos sentidos: no existe consenso en cuanto a su fecha de nacimiento y se desconoce cuándo y dónde murió; si bien existen indicios de su presencia en México, no se sabe con certeza cuánto tiempo estuvo aquí; tampoco se conoce alguna imagen de él, siendo que para la segunda mitad del siglo XIX la fotografía ya había llegado al país. En contraste, se conoce parte de su obra escrita, como la que ahora citamos.

En cierta consonancia con Lundy, Rhodakanaty cree ver en aquel México decimonónico como nación que se reconstruía, un gran laboratorio propicio para promover sus ideas en torno a cómo organizar a las sociedades. Con tal objetivo, en ese año comenzó a circular dicha Cartilla, que por su extensión (nueve lecciones en menos de veinte páginas) tenía más bien formato de folleto. Para los propósitos del presente trabajo, llama la atención que sus planteamientos se encuentren ubicados en el socialismo, pues se trata de una tendencia de pensamiento que en México no contaba con adeptos. Lo anterior se explica, pues era un momento en el que las facciones políticas e ideológicas se definían en torno al liberalismo desde las posturas más radicales (I. Ramírez o M. Altamirano, por ejemplo) hasta las moderadas (M. Otero o J. M. Vigil).

En lo que respecta propiamente al espacio geográfico actual de Chihuahua, a quienes estuvieron y escribieron sobre su paso por esa parte del norte mexicano, se tienen identificados a varios extranjeros. Uno de ellos es Philippe Rondé (1815-1883). Francés de origen y de espíritu aventurero, a este personaje se le atribuye una crónica intitulada Voyage dans l'état de Chihuahua (Mexique).? Este viajero también tuvo vena de artista, pues en su natal Francia trabajó como dibujante y retratista (en específico como pintor y grabador de interiores en recintos religiosos). Desde el título, su autor da indicios de la época en la que estuvo en la actual enti-

7 Vargas, Jesús (2003). Viajantes por Chihuahua (1846-1853), México, Gobierno del Estado de Chihuahua / Secretaría de Educación y Cultura, p. 150. Según Vargas, estos Viajes fueron editados por Édouard Chartón en una revista llamada Le tour du monde hacia 1861, "misma que se distinguió durante la segunda mitad del siglo XIX como la publicación francesa más importante en el tema de viajeros y crónicas de viaje por todo el mundo". 
dad fronteriza y los años que en allí permaneció, esto es, entre 1849 y 1852.

Si bien, este personaje se encuentra en un país convulso que acaba de ser invadido y derrotado por el ejército estadounidense, a Rondé parece no interesarle la situación política del país que visita (por demás caótica e inestable, que puso en entredicho la constitución del Estado nacional). En su relato abundan descripciones acerca de la vida cotidiana de las poblaciones que visita. Curiosamente, su trayecto por suelo mexicano es por el norte de lo que había quedado tras la redefinición de la frontera con Estados Unidos; así, su estancia en América habría comenzado por el Este norteamericano (en este caso, Nueva York), para continuar hacia el arco norte del Golfo de México (Nueva Orléans) hasta llegar a Matamoros. Ya en México, pasará por lugares de Tamaulipas y Coahuila para culminar en Chihuahua al mediar 1849.

Además de las menciones a ciertos aspectos cotidianos, destacan en esta obrita los grabados, bocetos y mapas con los que el autor complementó su diario de viaje. ${ }^{8}$ En ellos hace alusión a los lugares y regiones donde estuvo, así como las rutas que siguió; desde Presidio del Norte (hoy Ojinaga) hasta Janos, desde la capital (Chihuahua) hasta Paso del Norte (hoy Juárez). El aspecto mencionado podría equiparar a Rondé con la llegada y estancia de otro tipo de viajeros, quienes traían consigo una entonces novedosa técnica para captar paisajes (ciudades, pueblos, montañas, lagunas, sembradíos, etcétera) o "registrar" tipos (clases consideradas altas en lo social y económico, etnias indígenas, vagabundos, ladrones, prostitutas, etcétera): la fotografía. ${ }^{9}$

8 El ejercicio de Rondé es una tendencia en ese momento. Al mediar aquella centuria, en distintos países se elaboran "registros de tipos" que acompañan a diversas publicaciones para representar clases, segmentos y nacionalidades. Por ejemplo, en Inglaterra se publica Head of the people [1838-1840], en Francia Les Français peints par eux-mêmes [1839-1842] y en España Los españoles pintados por sí mismos [1842-1844]. En México, los trabajos mencionados incidieron en la obra Los mexicanos pintados por sí mismos [1854-55]. Ver: Pérez-Salas, María Ester (2005) Costumbrismo y litografía en México: un nuevo modo de ver, México, Universidad Nacional Autónoma de México-Instituto de Investigaciones Estéticas.

9 La versión canónica indica que la fotografía llegó a México en 1839 por Veracruz. Entre los personajes que arribaron al país para ejercer el oficio de fotógrafo se encontraba François Aubert. En lo que concierne al norte de la república, la innovación técnica llegó a la zona del Río Bravo vía Baltimore. Véase Aguilar Ochoa, 
La estancia de Rondé en estas tierras norteñas habría culminado hacia 1852, fecha que coincide con el lapso en el cual los límites geográficos entre México y Estados Unidos toman sus dimensiones definitivas.

En relación con el mencionado suceso, otro extranjero que escribió sus reflexiones acerca de esta entidad fue John Russell Bartlett (1805-1886). Oriundo de Nueva Inglaterra (en este caso, Rhode Island), este estadounidense contaba con una sólida preparación que le permitió estudiar a profundidad procesos históricos, aspectos lingüísticos, cuestiones étnicas e indagó sobre genealogía.

Lo anterior también lo desarrolló -al menos por un tiempo-, en asuntos oficiales concernientes a la política. En este punto el trabajo de nuestro personaje lo llevó -quizá por azar-, a vincularse con México y en especial con la entidad que aquí nos ocupa. Como se conoce, hacia 1848 se considera saldado el conflicto militar entre ambos países. El siguiente paso fue, en consecuencia, fijar los límites entre ambos Estados. De tal manera, a inicios de aquel año -específicamente el 2 de febrero-se firmó el primero de dos tratados, con los cuales la situación culminaría. ${ }^{10}$

En el periodo que va del mencionado tratado hasta 1853, la figura de Bartlett se verá inmersa en el proceso no de manera fortuita. Al mediar aquella centuria, nuestro autor ya se encontraba en las vastas regiones del Southwest norteamericano. Interesado en algunos de los grupos étnicos del suroeste de Estados Unidos y del norte de México, la clase política en Washington le encomienda encabezar una nueva etapa de la comisión encargada de

Arturo (2001). La fotografía durante el Imperio de Maximiliano, México, Universidad Nacional Autónoma de México-Instituto de Investigaciones Estéticas; Elizondo Elizondo, Ricardo (2006). Pliegues en la membrana del tiempo. Fotografía y correspondencia en el noreste de México 1840-1870, Monterrey, Fondo Editorial de Nuevo León.

10 Tamayo P. de Ham, Luz María Oralia (2001). La geografía, arma científica para la defensa del territorio, México, Universidad Nacional Autónoma de México / Instituto de Geografía / Plaza y Valdés, pp. 27 y 90-93. Aquí se explica de forma detallada que el conflicto inició en mayo 10 de 1846 y habría culminado en septiembre 14 de 1847. Después siguieron el Tratado de paz, amistad y límites de Guadalupe-Hidalgo (2 de febrero, 1848) y el Tratado de La Mesilla o Gadsden (30 de diciembre, 1853). A la par, cada país conformó sus comisiones, cuyo trabajo de campo desarrollaron entre 1849 y 1855. 
establecer los nuevos límites. Así, la estancia de nuestro autor en dicha encomienda iría desde 1850 hasta 1852.

Fruto de esta experiencia, Bartlett publicó un par de años después un trabajo intitulado A personal narrative of explorations and incidents in Texas, New Mexico, California, Sonora, and Chihuahua. ${ }^{11}$ Por lo que corresponde a la última región mencionada y según su escrito, el yankee ${ }^{12}$ habría permanecido en dicha entidad poco más de un mes. ${ }^{13}$ Pese al breve lapso de su estancia (su primera anotación indica el 6 de octubre y la última es del 12 de noviembre), llama la atención lo detallado de sus "apreciaciones" presentadas a manera de informe para la mencionada Comisión.

Contemporáneo al personaje anterior, aparece en nuestro elenco Julius Froebel (1805-1893). Activo desde los planos político e intelectual, este alemán trabajó para el New York Tribune siendo corresponsal en Centroamérica, así como en lugares recién delimitados por la frontera entre México y Estados Unidos. Resultado de dicha experiencia, hacia 1859 le publican un libro intitulado Seven years' travel in Central America, Northern Mexico, and the far West of the United States. Lo relatado sobre Chihuahua en este trabajo fue debido a su estancia de medio año en la entidad; habría llegado al Paso del Norte (hoy Juárez) a principios de noviembre de 1852, se internó en el mencionado territorio y retornó al punto de inicio en abril del año siguiente. ${ }^{14}$

Según se desprende de sus páginas, Froebel habría estado en tres regiones de la entidad: el norte, con epicentro en la actual Ciudad Juárez; el centro, en torno a la capital del estado; y la zona occidental, que domina la Sierra Madre. Llama la atención la vena

11 Una versión al castellano fue editada por la Universidad Autónoma de Ciudad Juárez en 1988 en el volumen Chihuahua: textos de su historia, 1824-1921. En 2003, Jesús Vargas Valdés vuelve a presentar el escrito en Viajantes por Chihuahua, 1846-1853. 12 Nos referimos al gentilicio que designa al oriundo de Nueva Inglaterra (como es el caso de Bartlett) y no al sentido despectivo que suele otorgársele a lo relacionado con Estados Unidos.

13 Vargas, J., Viajantes por Chihuahua..., op. cit., p. 200. En esta versión acompañan al texto de Bartlett dibujos y bocetos sobre ciertas situaciones que apreció en este estado (desde panorámicas de lugares como Chihuahua o Paso del Norte con sus respectivas catedrales y suburbios hasta escenas cotidianas en donde arrieros y agricultores hacen sus faenas).

14 Vargas, J., Viajantes por Chihuahua..., op. cit., p. 245. 
de escritor del personaje, pues ofrece espléndidos detalles del día a día (labores cotidianas, inseguridad, corrupción), de los paisajes que le causaron admiración (lagunas, cumbres, fauna, vegetación, jardines, huertas), incluso del clima (comenta algo sobre "remolinos y columnas de polvo").

Tras el recuento hecho, ¿qué rasgos es posible encontrar en los personajes mencionados? Un primer aspecto a indicar es el origen de los escritores que hemos considerado; en los casos aludidos todos fueron extranjeros. Otro aspecto a destacar es que usaron la escritura como instrumento para plasmar sus reflexiones sobre un entorno que les llamó la atención. Asimismo, se trató de individuos con ciertas habilidades (dibujar) y preparación (leer y escribir, hablar otros idiomas, ejercer algún oficio). Por distintos motivos los personajes mencionados llegaron a un país que parecía no decidirse a existir. Tal condición es la constante en sus relatos: guerras civiles, luchas intestinas, inseguridad, corrupción, enfermedades y epidemias. Ahora conocemos el desenlace: México superó sus problemas y consolidó un Estado nacional. Sin embargo, en ese tiempo no se sabe qué pasará con esta nación.

Si dichas problemáticas vigentes entonces no fueron un impedimento para estos autores, ¿qué les atrajo de un entorno que -a decir de sus testimonios- era convulso y riesgoso? Una posible argumentación la encontramos en el Romanticismo, movimiento surgido en Europa hacia fines del siglo XVIII y primeras décadas del XIX, que delineó la orientación intelectual de tendencias filosóficas, artísticas y literarias. ${ }^{15}$ Entre los puntos que destacan los autores románticos estarían lo "primitivo", lo "joven", pero también lo "extraño", lo "exótico", lo "grotesco", lo "misterioso", lo "sobrenatural", las "costumbres". Entre sus planteamientos está presente la revaloración de las tradiciones y culturas más allá de la órbita occidental (señaladamente marcada por el horizonte judeocristiano). De esta forma, no es gratuito que a los integrantes

15 Berlin, Isaiah (2000). Las raíces del Romanticismo, Madrid, Grupo Santillana, edición de Henry Hardy, traducción de Silvina Marí, p. 27. Berlin apunta que una "gran ruptura" se habría originado en lo que hoy es Alemania entre 1760 y 1830, lo cual supuso "ese gran quiebro en la conciencia europea". En esta línea argumentativa, cabría mencionar a H. Heine (en lo que hoy es Alemania), W. Scott (Escocia), F. R. de Chateaubriand (Francia) y J. Zorrilla (España). 
de esta corriente de pensamiento les causara fascinación la experiencia europea anterior al cristianismo (sus tradiciones paganas, por ejemplo) y sintieran una obsesiva atracción por la Edad Media (hasta la fecha, periodo considerado de atraso y oscurantista en el cual aquellas "generaciones románticas" consideraban encontrar aportaciones relevantes que debían ser conocidas, estudiadas y difundidas). Todavía más, la pléyade de artistas e intelectuales adscrita a dicha tendencia comenzó a sentir atracción por otras civilizaciones cuyo exotismo los "hechizó", de tal manera que el antiguo Egipto, así como las culturas de India, China o Japón comenzaron a ser contempladas, valoradas y exaltadas. ${ }^{16}$ La América de herencia indígena e hispánica (de la cual México forma parte), muy bien cabe en tales postulados.

Los autores aquí considerados tienen rasgos que los definirían como románticos, lo que de algún modo les hizo preguntarse si había algo más allá de sus respectivos entornos históricos, culturales, idiomáticos o religiosos. En consonancia con lo anterior, es posible que estas condiciones hayan sido las que llamaron la atención de los personajes abordados páginas arriba, en un lugar (México y específicamente Chihuahua) que les pareció atractivo por "extraño", "misterioso" y "grotesco". Por tanto, sugerimos que lo anterior les pudo haber impulsado a buscar aventuras que difícilmente habrían experimentado en sus lugares de origen, de ahí la necesidad de ir al encuentro con aquello que consideraron distinto y atractivo.

\section{GEORGE RUXTON EN MÉXICO}

¿Es posible ubicar en este ambiente al escritor que impulsa nuestro trabajo? Para responder a lo anterior, retomamos y presentamos algunos datos. George Frederick Augustus Ruxton (1821-1848) era inglés y fue uno de los tantos extranjeros que estuvieron en

16 En ese ambiente, los interesados en los estudios científicos de culturas antiguas (denominados "orientalistas") impulsaron el desarrollo de disciplinas como la Historia, la Arqueología o la Antropología. Puede decirse, por tanto, que las y los historiadores somos en cierta forma herederos del Romanticismo. 
México en aquella centuria. ${ }^{17}$ De hecho, como "escritor viajero" estuvo en lugares de España, la parte central de África y el oeste de Estados Unidos. Al parecer, tuvo el mérito de ser reconocido por instituciones británicas que por aquel tiempo hacían y promovían trabajos científicos en distintas áreas, en este caso, la Royal Geographical Society y The Ethnological Society. ${ }^{18}$ A diferencia de los otros personajes mencionados, este autor murió muy joven; pese a ello, logró ver publicada su obra. Aparentemente, las notas mediante las que habría elaborado su manuscrito se perdieron. Lo anterior le obligaría a reescribir aquellas impresiones que originalmente redactó. El resultado fue Adventures in Mexico and the Rocky Mountains ${ }^{19}$ publicado en Londres por John Murray en 1847.

Su estancia en México data de 1846, con el inicio de la invasión del ejército estadounidense. Como aventurero, su interés radicaba en ser testigo del acontecimiento. Llegaría a Veracruz en

17 Vargas, J., Viajantes por Chihuahua..., op. cit., p. 37. Aquí se describe al escritor en estos términos: "Fue un viajante atípico que se interesó en escribir sistemáticamente todo lo que le llamaba la atención de los mexicanos".

18 Ruxton, George (1974). Aventuras en México, versión al español de Raúl Trejo, México, Ediciones El Caballito. Así lo indica esta edición en la portada interior. En nuestro país, por esa época podemos mencionar a la Sociedad Mexicana de Geografía y Estadística. Dicha institución (llamada así desde 1849), se fundó en 1833 como el Instituto Nacional de Geografía y Estadística (INEGI) con el propósito de recolectar datos e información que sirvieran a la clase gobernante para tomar decisiones respecto a qué tipo de Estado mexicano debía constituirse. El Boletín comenzó a circular en 1839 con colaboraciones de la élite política e intelectualmente activa de la época. A los colaboradores se les denominaba "socios" y había rangos que los identificaban (socios de número, socios honorarios, socios corresponsales en las entidades de la república y socios en el extranjero). Todos estudiaban distintos aspectos de la realidad nacional, como conocer la población, el territorio y sus recursos naturales, y también se ocupaban de ciertas problemáticas sociales (criminalidad, prostitución, vagancia) con el objetivo de encontrar parámetros que "normaran" a la sociedad de su tiempo. Sus trabajos y registros los desarrollaron desde una perspectiva de ciencia mecanicista y determinista. A lo largo del siglo XIX, en dicha empresa se involucraron los personajes más destacados de distintas generaciones.

19 Ruxton, G., pp. 11 y 12. En el prefacio, el autor expone: "Este pequeño trabajo pretende ser simplemente, como su título lo indica, las notas generales de un viaje a través de México y un invierno entre los escenarios naturales y los salvajes personajes de las Montañas Rocallosas”. Para la referida versión editada en México, en el mismo prefacio se introduce una nota a pie de página que indica: "El editor consideró inútil imprimir en español la travesía de Ruxton por las montañas rocosas". Lo anterior justifica que hagamos referencia de la obrita en el idioma original, pues incluye el título completo con sus notas acerca de la estancia del autor en esa parte del suroeste de Estados Unidos. 
agosto de aquel año y de ahí se habría internado a zonas de como Aguascalientes, Zacatecas, Durango y Chihuahua. Continuaría más tarde desplazándose por Estados Unidos al Suroeste (Nuevo México, Colorado, Utah) y después al centro (en este caso Missouri, donde muere debido a una enfermedad). En la travesía, su contacto con las fuerzas armadas norteamericanas y con pueblos nativos le servirán para recrear páginas que más tarde se publicarán como libros de manera póstuma. Hasta aquí es posible advertir un primer indicio: el vínculo geográfico e histórico del suroeste estadounidense y norte mexicano queda plasmado en la travesía de nuestro personaje.

En nuestro país, las Aventuras aparecerán en castellano hasta 1974 con la versión de Raúl Trejo y un Prólogo de Fausto Castillo en la edición de El Caballito. Nueve años más tarde, la misma casa editorial volvería a presentarlo. En este trabajo editorial, llama la atención que los párrafos precedentes al texto del "viajero literato" presten atención al asunto de la "patriotería" y al "patriotismo". Como mexicanos, somos dados a la victimización y, si se trata de Estados Unidos, la historiografía en nuestro país (en especial la "oficialista"), está plagada de ejemplos en innumerables páginas. Si bien, como se nota en la escritura de este inglés, existió indolencia entre los mexicanos de entonces (sin importar clase social ni dónde se encontraran) en relación con la invasión del ejército estadounidense y su desenlace, más que describir el suceso como "canallada", nos inclinamos por acercarnos a esta obrita con la intención de encontrarle su sentido, esto es, por qué el autor escribió sus notas en un momento determinado. Trataremos, hasta donde nos sea posible, de dejar que la "fuente" se exprese y muestre al lector de forma directa la escritura elaborada por el protagonista de esta historia.

\section{UN “CIVILIZADO” ENTRE "BÁRBAROS” (O CÓMO UN INGLÉS RECORRIÓ CHIHUAHUA)}

Según los parámetros decimonónicos de corte evolucionista aplicados a lo social y cultural, la Inglaterra victoriana habría sido el 
modelo de una sociedad civilizada. ${ }^{20}$ El resto de las sociedades y culturas (africanas, asiáticas, americanas, incluso otras de Europa como latinas o eslavas), quedarían "atrasadas" en algún grado. La literatura de la época ofrece elocuentes referencias al respecto. Tomemos como muestra la argumentación que Bram Stocker (1847-1912) expone en Drácula. A grandes rasgos, se trata de un personaje (Conde Drácula) oriundo de los Cárpatos (en la actual Rumania) que se desplaza a la Inglaterra de fines del siglo XIX. La historia de horror publicada hacia 1897 relata los "males", "problemas" y "amenazas" que supone la presencia de este extraño de Europa del Este en el corazón del "civilizado" Imperio Británico.

¿Es posible ubicar a nuestro autor en este argumento? ¿Cómo representa Ruxton a México (en este caso Chihuahua) y a los mexicanos? Para acercarnos a la lectura de este personaje proponemos dos aspectos presentes en su escritura: la geografía (o paisajes) y la vida cotidiana (trato con las personas en los lugares que estuvo). Lo anterior nos permitirá reconstruir cómo era esta parte del norte de México al mediar el siglo XIX a través de la mirada de un extranjero.

El texto que hemos elegido para este ensayo muy bien puede apreciarse en los términos planteados: se encuentra en la mitad del XIX y relata el contacto de un inglés ("civilizado") con una parte del pueblo mexicano ("bárbaro"). En este escrito buscamos encontrar cómo se representaba de manera geográfica y cultural a Chihuahua y sus habitantes.

¿Qué lugar ocupa nuestra entidad en el relato? Un indicio lo encontramos en el orden que compone el libro. Así, en la versión al castellano del texto referido, este tiene 245 páginas divididas en XXIV capítulos. En su estructura, el índice nos muestra el itinerario del inglés: inicia en Veracruz (entonces entrada y salida a México de mercancías, de personas y de ideas); pasa por Puebla, la ciudad de México, Querétaro, Silao, Aguascalientes, Durango y

20 La reina Victoria (1819-1901) encabezó la monarquía británica desde 1837 hasta su muerte. Dicho periodo supuso el advenimiento de cambios derivados de diversos procesos (industriales, científicos, tecnológicos, económicos, sociales, demográficos) y marcó la hegemonía del imperio británico a nivel mundial (esto es, una quinta parte del orbe). 
el Mapimí; llega a Chihuahua y culmina en Estados Unidos (en este caso, Texas y Nuevo México). Por lo que respecta a la entidad en la cual nos enfocamos, sus "notas" inician en el capítulo XIX y terminan en el XXI (esto es, de la página 181 a la 213).

Ya se señaló: viajar a México en el siglo XIX significaba viajar a un lugar místico y exótico que podía ofrecerle al mundo cosas tan raras como las que ofrecían los entonces recientes descubrimientos en Egipto, las incursiones al Asia o inmiscuirse en las selvas africanas. Así de venturoso resultó para nuestro personaje viajar a estas latitudes: "El México independiente despliega sus bellezas exóticas para que otros sigan las huellas del Gran Viajero, el Barón de Humboldt, y hagan correr de boca en boca, la leyenda de las riquezas inagotables de nuestras minas y nuestro suelo", ${ }^{21}$ se lee en la introducción a las Crónicas de viajeros que recopiló la Secretaría de Obras Públicas en un volumen dedicado a estos escritos de extranjeros durante aquella centuria.

Así como los extranjeros reinventaban a México y a los mexicanos, se dice en esta obra que también los mexicanos representaban al extranjero. Baste la siguiente alusión: "El mexicano descubre e inventa también al extranjero. Lo descubre cuando lo advierte, sólido y ridículo, buscando ruinas o excavando minas, extasiándose ante el paisaje y mirando con asombro el color local". ${ }^{22}$ Lo anterior significa que, como dos bolas de billar que chocan sobre el manto verde, tanto oriundos como extraños cargan con su propia inercia, su "energía cinética". El encuentro resulta un instante, como una fotografía en la cual unos y otros tratan de reconocerse.

Como hemos argumentado, para muchos europeos -sobre todo franceses, alemanes e ingleses- viajar a México era redescubrir el mundo. Viajaban a lugares como América, Asia y África con la intención de conocer aquello que no era occidental. Un ejemplo de estos escritos que analizamos para nuestro ensayo es George Ruxton.

21 Ruxton (1972). Viajes en México: crónicas extranjeras (1821-1855). México, Secretaría de Obras Públicas, p. 11.

22 Op. cit., p. 12. 
El itinerario de este viajero inglés comenzó al salir de Southampton Water el 2 de julio de 1846 para llegar a Veracruz un mes después. ${ }^{23}$ En su libro Aventuras en México narra su viaje desde Veracruz a Puebla y de esta a la ciudad de México. Luego de estar en la capital mexicana y registrar su condición de suciedad e inseguridad, toma notas de su viaje por Aguascalientes, Zacatecas y Durango antes de su llegada a Chihuahua a través del Mapimí.

Ruxton menciona que una vez que salieron de Mapimí, pasaron por una villa cuyo espacio describe como un lugar abandonado hace algún tiempo, donde al parecer la maleza ha encontrado un lugar donde crecer y donde los gatos han decidido quedarse. El inglés también tiene la impresión de que el lugar ha sido ocupado por los indios para establecerse y cometer sus fechorías, pues dice que cuando registraban los interiores de la villa encontraron "restos de fuego reciente, y algunos guajes de indios, una flecha y una cabellera humana". ${ }^{24}$

De esta manera, nuestro personaje continúa narrándonos sus aventuras por la entidad y su estadía en la capital. Durante este viaje a la ciudad de Chihuahua no deja de mencionar la falta de sueño a causa de mantenerse alerta para cuidarse de los ataques de los indios. También son constantes las descripciones que hace de poblaciones desoladas, así como de la "poca gracia" de los mexicanos que se topa en el camino. Fue común durante aquella centuria que los extranjeros atestiguaran las miserias de la población mexicana (en particular la indígena, que era la mayoría): tirados en el suelo por calles y parques, descalzos, mendigando, muertos de hambre. Llama la atención que el inglés use una palabra decente y discreta para tomar nota de ello.

Para Ruxton, los mexicanos no son más que personas sin moral y poco agraciadas que no tienen virtud alguna, por lo cual no encuentra ningún valor en ellos. Y es que, dice:

Si los mexicanos poseen una sola virtud, y espero que así sea, deben tenerla guardada en algún secreto rincón de su "sarape" y esta debe haber escapado a mi humilde apreciación, aunque viajé por ese

23 Vargas, J., Op. cit., p. 37.

24 Ruxton, G., Op. cit., p. 156. 
país con los ojos bien abiertos y una disposición lista y bien despierta. Espero que, por su propio bien sacará rápidamente de su escondrijo solitario, la luz de esta virtud disimulada, si no, dentro de muy poco tiempo será absorbido por la potente flama que el anglosajón parece estar dispuesto a esparcir sobre el oscuro México. ${ }^{25}$

Otro ejemplo despreciativo es cuando confundió a uno de sus compañeros mexicanos con uno de los indios salvajes de los que tanto se estaban cuidando, pues dice:

Convencido de que no podía ser más que un indio, me tiré sobre la hierba y me aproximé sin hacer ruido. La figura también se acercaba e imaginé que sería un indio que no tardaría en disparar su arco sobre mí. Mi rifle estaba listo y a punto de tirar, cuando la figura cayó sobre sus rodillas implorando "no tire, por Dios, soy su amigo" y advertí que se trataba de uno de los mexicanos que, envuelto en su sarape café, con el cabello largo y la tez oscura y armado con arco y flechas, se parecía mucho a un indio. ${ }^{26}$

Lo anterior nos deja muy en claro que para Ruxton los mexicanos y los "indios salvajes" son exactamente iguales en lo físico y en lo mental, pues ninguno tiene "virtudes".

Otra parte llamativa es cuando Ruxton narra una cena que le ofrecieron en una villa cerca de la capital chihuahuense, donde admite que lo trataron muy bien y le sirvieron comida muy deliciosa. Así, en el siguiente pasaje parece que por primera vez encuentra una virtud de los mexicanos, pues apunta: "A la mañana siguiente estaba escribiendo en mi cuaderno, pensando en la hospitalidad que había encontrado en México, cuando llegó un mozo con la cuenta de la cena del día anterior: seis reales por la comida. Inmediatamente arranqué la hoja de mi libreta". ${ }^{27}$ Este pequeño episodio deja a la vista lo curioso que es para nosotros hoy en día este texto que, posiblemente, en su época sirvió para difundir una mala imagen de México.

25 Ibid., pp. 12-13.

26 Ibid., p. 164.

27 Ibid., p. 178. 
Una vez que Ruxton llega a Chihuahua, nos describe sus primeras impresiones de la capital del estado. De entrada, menciona que es una ciudad "semicivilizada" donde para entonces ya se ha establecido una comunidad inglesa. Dicha circunstancia es una tendencia, pues grupos de alemanes, estadounidenses o franceses con capital y cierto tipo de conocimiento, ven la posibilidad de explotar algún recurso natural (minerales, por ejemplo) y desarrollar alguna actividad comercial en varias partes del país. De igual manera nos menciona que en dicha ciudad viven entre ocho y diez mil habitantes, además de aquellos que llegan constantemente de Nuevo México, California y Sonora. ${ }^{28}$

Luego, el autor nos describe la Catedral y parece elogiarla al mencionar que es considerada por algunos estadounidenses como una de las más bellas del mundo con su fachada donde destacan los doce apóstoles. No obstante, y como era de esperarse, no tarda en matar el encanto al mencionar que frente a los portales "colgaban las cabelleras de 170 apaches que habían sido atrapados e inhumanamente asesinados por los cazadores de indios que paga el estado". ${ }^{29}$ Nos llama la atención la forma en que identifica la "barbarie" de la cual los indígenas son víctimas, siendo que -como se rescató en sus párrafos líneas arriba-, él mismo relata que estuvo a punto de asesinar a un mexicano "con pinta de indio".

George Ruxton menciona que Chihuahua es un buen lugar para que los extranjeros puedan ofrecer sus mercancías, pues al parecer todo se vende bien si las cosas tienen buena calidad. El gran problema es que en Chihuahua solo se usan monedas de cobre que difícilmente se pueden cambiar por oro o plata y, por consiguiente, solo pueden ser usadas en esa entidad. Y es que, en este mismo texto, su autor afirma que el comercio entre Chihuahua y los Estados Unidos es muy bueno, tanto que es "superior al millón de dólares". ${ }^{30}$ El dato anterior supone que, desde antes de 1846, esta parte del norte mexicano ya estaba integrada con lo que será el suroeste norteamericano.

28 Ibid., p. 181.

29 Ibid., p. 181.

30 Ibid., p. 182. 
A pesar de que Chihuahua es un buen lugar para generar riquezas a través de diversas actividades económicas y comerciales, los principales obstáculos que mira el extranjero son las grandes praderas secas llenas de indios que hay, las cuales deben cruzarse desde Santa Fe hasta Chihuahua para poder vender la mercancía (si es que esta no fue robada durante el camino).

Para Ruxton, el mayor problema de Chihuahua son los indios, y es que dice:

El Estado de Chihuahua produce oro, plata, cobre, hierro, salitre, etc., y sin duda solo es productivo en minerales porque el suelo es pobre y por todas partes escasea el agua. Además, está infestado de indios hostiles que depredan el campo y evitan que muchas de las minas más valiosas sean explotadas. Estos indios son los apaches, que habitan en las cordilleras y planicies de la Sierra Madre en el oeste, y las áreas situadas entre el Conchos y el Del Norte al este, y además hay tribus esparcidas por todo el Estado, devastando los ranchos y haciendas y despoblando las villas lejanas. ${ }^{31}$

La referencia anterior no puede ser más concreta: Chihuahua podría ser una entidad con cierto desarrollo gracias a la riqueza de sus minerales. No obstante, los apaches son el gran problema que acaba con todo asentamiento de mexicanos y extranjeros, en minas y haciendas. De hecho, tal condición resultó una constante para nuestro país tanto en la etapa novohispana como en la independiente, pues no será sino hasta la etapa porfiriana cuando la situación se considere "resuelta".

En este aspecto, el autor explica que los chihuahuenses han creado grupos para sostener una guerra contra los "salvajes". Así, se menciona que el gobierno ofreció recompensa de cincuenta dólares por cabellera para que todo el pueblo se involucrara en esta guerra contra los apaches. Aquí se nos narra un evento sumamente cruel: cuenta que un irlandés, Don Santiago Kirker, quien había sido comerciante de indios en el Lejano Oeste, se puso al frente de un grupo de doscientos cincuenta hombres y

31 Ibid., p. 183. 
algunos indios wanee y delaware para perseguir apaches y cobrar la atractiva recompensa. En el mes de agosto se dice que algunos apaches deseaban estar en paz, por lo que se acercaron sin armas a la villa de Galeana con el propósito de negociar. Este grupo de apaches era de 170 individuos, contando entre ellos a mujeres y niños. Cuando Kirker supo de esto, les mandó barriles de licor para que lo "disfrutaran" mientras él llegaba. Una hora después, llegó Kirker acompañado de los mexicanos y con sus armas masacraron a todos los apaches que habían ido a negociar; venganza y recompensa fueron los móviles de lo que ahora identificaríamos como genocidio.

Resulta que las 170 cabelleras que Ruxton apreció en la fachada de la Catedral cuando llegó por primera vez a la capital, eran de este grupo de indígenas. Pero los horrores de la ominosa historia continúan, pues este autor nos cuenta que después de estos ataques una mujer apache embarazada logró escapar y llegó hasta la iglesia para pedir clemencia. Pese a su ruego, el grupo de mexicanos no tuvo compasión por ella y la atravesaron con una docena de lanzas, luego extrajeron de su vientre al bebe aún vivo, lo bautizaron y acto seguido le destrozaron la cabeza estrellándolo contra la pared de la iglesia. ${ }^{32}$

Una vez leída la descripción que hace nuestro personaje de semejantes atrocidades, nos es difícil distinguir lo "bárbaro" entre los mexicanos, los apaches y los extranjeros asentados. Por lo anterior, tenían que hacer frente a los constantes ataques de los apaches, con el respectivo rencor y odio que les guardaban hasta poder vengarse. No había honor ni justicia, era un despiadado ajuste de cuentas. Dicho pasaje que parece una auténtica escena del infierno, nos muestra la realidad de la época: un entorno donde cada individuo y comunidad fronterizas debían arreglárselas para sobrevivir.

Una vez que Ruxton nos ha descrito estos hechos terribles que cometieron los mexicanos guiados por el interés monetario del irlandés Kirker, pasa a redactarnos una especie de lista de la gran variedad de fauna que existe en la entidad. Así, elabora una lista

32 Ibid., p. 184.

Chinuahua Hoy 2016 
de especies como tipos de osos, lobos, ciervos, jabalíes, liebres, conejos, gamos, aves, insectos, reptiles y serpientes. "Chihuahua es un paraíso para los cazadores", remata maravillado Ruxton en una parte de su texto. ${ }^{33}$ Décadas más tarde, al final de ese siglo, comenzarán a percibirse los excesos de la caza indiscriminada en Norteamérica con animales como el lobo y el búfalo. Y es que, efectivamente, entonces las personas consideraban que la naturaleza era inagotable.

Otra cosa que trata nuestro viajero es el tema de las tropas mexicanas en el momento de la invasión del ejército estadounidense. Al respecto, narra la precariedad y penurias en las que dichas tropas se encontraban. Por lo anterior, no le sorprende que 900 soldados estadounidenses -que solo eran leñadores mal pagados-, hayan vencido a un contingente de tres mil soldados mexicanos sin perder un solo hombre. Así, nos menciona el ejemplo de un trío de ellos que lo acompañaron en su viaje al Paso del Norte y dice:

Les prestaron caballos -flacos, medio desnutridos- para esa ocasión y los hombres, que habían rehusado partir sin tener alguna provisión para el camino recibieron su "sueldo" de un patriota comerciante de la ciudad que dio a cada uno un puñado de monedas de cobre, que ataron cuidadosamente en las esquinas de sus sarapes. Uno tenía un sucio sombrero de paja, el otro un trozo de chaqueta, el otro estaba en mangas de camisa, con overoles abiertos que le llegaban un poco más debajo de las rodillas. Estaban mal armados. Uno tenía una rústica espada y una lanza, y el otro un rifle sin cacha, el tercero un arco y flechas. Aunque las noches prometían ser frías, solo llevaban un raquítico sarape y no tenían raciones de ninguna clase. ${ }^{34}$

La cita anterior nos expone de manera clara los problemas en los que vivían los "soldados" chihuahuenses, no solo en la cuestión de entrenamiento militar, sino en lo referente a indumentaria propia para el combate y las condiciones económicas. Dicha condición es contundente en este párrafo porque, por un lado, los

33 Ibid., p. 185

34 Ibid. pp. 188 y 189. 
soldados no habían recibido provisión alguna para el viaje; por otro, tampoco recibían su sueldo, razón por la cual es probable que de no ser por ese pequeño puñado de monedas de cobre que les "pagó" un "patriota comerciante de la ciudad", habrían ido al combate aun en peores condiciones.

\section{CONSIDERACIONES FINALES}

El concepto que priva para identificar autores y obras como los referidos en este trabajo es el de "literatura de viajes". En dicha propuesta literaria predomina -como vimos-, la observación del testigo, del personaje que estuvo en un lugar determinado en un momento específico, así como la narración en primera persona. Bajo esta premisa, qué podríamos destacar de los extranjeros que estuvieron en México en aquella centuria. En el presente ejercicio, fue posible identificar al menos tres aspectos generales: una presencia y permanencia en entornos geográficamente alejados y de difícil acceso (en este caso, escenarios rurales); una peculiar fascinación por parte de los observadores (que en ocasiones plasmaron en sus crónicas de forma mística) ante lo que ellos captaban como exótico; y un contacto de estos "escritores viajeros" con segmentos de la población mexicana comúnmente marginales según la rígida estratificación social de la época.

En los casos considerados se trató de extranjeros que no tuvieron el español como lengua materna. Otros personajes también lo experimentaron, pues en la misma condición durante el siglo xIx se encontraron los italianos C. Linatti y F. Galli, el inglés H. G. Ward, el alemán J. M. Rugendas, el checo F. Waldeck, así como los franceses M. de Fossey y M. Chevalier. Por otra parte, es necesario decir que otros extranjeros que a principios de aquella centuria arribaron a nuestro país lo hicieron desde lugares de la órbita y tradición hispanoamericana (sirva de ejemplo la presencia y obra de J. M. Heredia a quien se le considera el introductor del Romanticismo en México). Así, desde utopistas hasta empresarios, desde aventureros hasta colonizadores, todos ellos dejaron una visión que ahora tomamos como objeto de estudio, lo cual nos permite comprender un periodo formativo para México: la centuria deci- 
monónica, momento en que se abandonó el esquema colonial y se constituyó un Estado que aspiraba a la modernidad.

Ahora bien, las representaciones a partir de lo escrito también fueron elaboradas por mexicanos que durante aquella centuria se encontraron por algún tiempo en Europa. Los casos de Juan Nepomuceno Adorno y Santiago Rebull son muestra del quehacer de mexicanos cuya estadía en el "viejo continente" les animó a representar lo que veían y experimentaban. Pero quizá el caso de Manuel Payno sea el más apegado a nuestros argumentos, pues como encargado de la legación de México en Londres, plasmó sus experiencias en unas Memorias e impresiones de un viaje por Inglaterra y Escocia. Si los viajeros aludidos en estas páginas ven en México un lugar donde desborda el exotismo (con sus riesgos y oportunidades), Payno no tiene empacho en externar su admiración por los británicos (y, de hecho, por la cultura Occidental). ${ }^{35}$

¿Qué decir de la crónica de Ruxton respecto a Chihuahua? En sus argumentos, nos fue posible encontrar dos grandes vetas que contrastan entre sí: por un lado, destaca (en ocasiones hasta el grado de cebarse) lo que pondera como las limitaciones, los defectos y los vicios de los mexicanos (traición, indolencia, apatía, incapacidad); por otro, desglosa (en no pocas veces con lujo de detalle y ánimo desbordado) las bellezas de los lugares que visitó y los recursos naturales existentes en el aún vasto territorio de la nación. Lo anterior se entrelaza con un planteamiento muy socorrido a lo largo de aquella centuria entre la élite gobernante de nuestro país: la necesidad y conveniencia de atraer colonos para las diversas regiones. Pero no pensaban en cualquier tipo de colono, pues debía ser portador de cierto perfil: racional, moderno, que conociera y practicara algún oficio, de ser posible que contara con capital, preferentemente católico y, por supuesto, blanco. Si, como expone nuestro autor, la nación tenía potencial ilimitado gracias a sus recursos naturales y los mexicanos no tenían la capacidad ni el carácter para explotarlo, la solución era promover la colonización por parte de europeos o estadounidenses.

35 Illades, Carlos (2005). Nación, sociedad y utopía en el romanticismo mexicano, México, Sello Bermejo/Consejo Nacional para la Cultura y las Artes, pp. 47-51. 
Por otra parte, el texto de Ruxton es rico desde el punto de vista de ofrecer un registro sobre distintos aspectos; así, la flora y la fauna de la época, del carácter de los mexicanos, su forma de vestir, el papel que juegan los extranjeros, el comercio, los constantes ataques de los apaches y las crueles venganzas que los mexicanos hacían contra ellos, son cuestiones que atraviesan la narrativa del inglés aventurero.

Consideramos que el texto de Ruxton puede ser útil para entender no solo a Chihuahua, sus habitantes y su naturaleza en el siglo XIX; también brinda la posibilidad de entender a los extranjeros, su forma de ver y sus intereses a la hora de escribir tal o cual cosa sobre un país tan atractivamente exótico en aquella época como lo fue México y sus particularidades en cada región. Pese a la honestidad -casi siempre brutal- de sus argumentos acerca del país y de sus habitantes, la descripción elaborada por este extranjero errante nos ha servido como objeto de estudio para acercarnos a una etapa de la historia de México convulsa que, pese a todo, se logró superar.

Por último, nos llama la atención que el rescate y presentación de esta crónica -al menos a la que tuvimos acceso- haya tomado más de una centuria. Quizá una posible respuesta esté en la victimización que ha acompañado el carácter de las y los mexicanos, sobre todo si tomamos en cuenta la representación negativa que este súbdito del Imperio Británico elaboró respecto a nuestro país. En tal sentido, los epígrafes de Novalis y Camus están en consonancia con la experiencia de nuestro autor: por una parte, la "posteridad" nos ha permitido conocer -acaso de manera tardía- estas reflexiones adustas acerca de una época; por otra, conocemos dichas reflexiones gracias a que este personaje "trabajó", "amó" y "murió" en esos lugares que "descubrió". 


\section{BIBLIOGRAFÍA}

Aguilar Ochoa, A. (2001). La fotografía durante el Imperio de Maximiliano, México, Universidad Nacional Autónoma de México-Instituto de Investigaciones Estéticas.

(1972). Viajes en México: Crónicas extranjeras (1821-1855), México, Secretaría de Obras Públicas.

(2011). Tiempos de Tormenta. La vida en Monclova, Coahuila; Ciudad Victoria y Matamoros, Tamaulipas, 1833 y 1834/Diario de Benjamin Lundy, Estudio introductorio, traducción y notas de J. Villarreal Lozano, Saltillo, Universidad Autónoma de Coahuila/Escuela de Ciencias Sociales/Plaza y Valdés.

Berlin, I. (2000). Las raíces del romanticismo, Madrid, Grupo Santillana, Edición de Henry Hardy, Traducción de Silvina Marí.

Corvera Poiré, M. (2005). "Las guías de forasteros en el México del siglo XIX", La República de las Letras. Asomos a la cultura escrita del México decimonónico, Vol. II, Publicaciones periódicas y otros impresos, edición Belem Clark de Lara y Elisa Speckman Guerra, México, Universidad Nacional Autónoma de México.

Elizondo Elizondo, R. (2006). Pliegues en la membrana del tiempo. Fotografía y correspondencia en el noreste de México, 1840-1870, Monterrey, Fondo Editorial de Nuevo León.

Espinosa Martínez, E. I. (2009). “La construcción de lo 'nacional' desde las regiones. La Revista de Nuevo León y Coahuila, 1863-64”, Vetas. Revista de El Colegio de San Luis, número 30, año X, enero-junio.

Illades, C. (2005). Nación, sociedad y utopía en el romanticismo mexicano, México, Sello Bermejo/Consejo Nacional para la Cultura y las Artes.

(2002). Rhodakanaty y la formación del pensamiento socialista en México, México, Anthropos/Universidad Autónoma Metropolitana-Iztapalapa.

Mentz, B. von (2011). “¿Espía prusiano?, ¿cortesano liberal?, ¿científico apolítico? Notas en torno al autor del Ensayo político sobre el reino de la Nueva España y del Cosmos, y el contexto prusiano-alemán en que vivió (1769-1859)", J. E. Covarrubias y M. Souto Mantecón (Coord.), Economía, ciencia y política. Estudios sobre Alexander von Humboldt a 200 años del Ensayo político sobre el reino de la Nueva España, México, Instituto 
Mora/Universidad Nacional Autónoma de México-Instituto de Investigaciones Históricas.

Morfi, J. A. (1980). Viaje de indios y Diario de Nuevo México, Nota bibliográfica y anotaciones por V. A. Robles, México, Librería Manuel Porrúa [Documentos Mexicanos].

Pérez Salas, M. E. (2005). Costumbrismo y litografía en México: un nuevo modo de ver, México, Universidad Nacional Autónoma de México-Instituto de Investigaciones Estéticas.

Ruxton, G. (1974). Aventuras en México, traducción de Raúl Trejo, México, Ediciones "El Caballito".

Tamayo P. de Ham, L. M. O. (2001). La geografía, arma científica para la defensa del territorio, México, Universidad Nacional Autónoma de México/ Instituto de Geografía/Plaza y Valdés.

Vargas, J. (2003). Viajantes por Chihuahua (1846-1853), México, Gobierno del Estado de Chihuahua/Secretaría de Educación y Cultura. 